\title{
Review
}

\section{Mitochondrial Iron Metabolism and Its Role in Neurodegeneration}

\author{
Maxx P. Horowitz ${ }^{\mathrm{a}, \mathrm{b}, \mathrm{c}}$ and J. Timothy Greenamyre $\mathrm{b}^{\mathrm{b}, \mathrm{c}, \mathrm{d}, *}$ \\ ${ }^{a}$ Medical Scientist Training Program, University of Pittsburgh, Pittsburgh, PA, USA \\ ${ }^{\mathrm{b}}$ Center for Neuroscience, University of Pittsburgh, Pittsburgh, PA, USA \\ ${ }^{\mathrm{c}}$ Department of Neurology, University of Pittsburgh, Pittsburgh, PA, USA \\ ${ }^{\mathrm{d}}$ Pittsburgh Institute for Neurodegenerative Diseases, University of Pittsburgh, Pittsburgh, PA, USA
}

Accepted 16 April 2010

\begin{abstract}
In addition to their well-established role in providing the cell with ATP, mitochondria are the source of iron-sulfur clusters (ISCs) and heme - prosthetic groups that are utilized by proteins throughout the cell in various critical processes. The post-transcriptional system that mammalian cells use to regulate intracellular iron homeostasis depends, in part, upon the synthesis of ISCs in mitochondria. Thus, proper mitochondrial function is crucial to cellular iron homeostasis. Many neurodegenerative diseases are marked by mitochondrial impairment, brain iron accumulation, and oxidative stress - pathologies that are interrelated. This review discusses the physiological role that mitochondria play in cellular iron homeostasis and, in so doing, attempts to clarify how mitochondrial dysfunction may initiate and/or contribute to iron dysregulation in the context of neurodegenerative disease. We review what is currently known about the entry of iron into mitochondria, the ways in which iron is utilized therein, and how mitochondria are integrated into the system of iron homeostasis in mammalian cells. Lastly, we turn to recent advances in our understanding of iron dysregulation in two neurodegenerative diseases (Alzheimer's disease and Parkinson's disease), and discuss the use of iron chelation as a potential therapeutic approach to neurodegenerative disease.
\end{abstract}

Keywords: Alzheimer's disease, FBXL5, iron, iron regulatory protein, iron-sulfur cluster, mitochondria, neurodegeneration, Parkinson's disease

\section{INTRODUCTION}

Mitochondrial dysfunction is a prominent feature of many neurodegenerative diseases. These organelles are arbiters of cell death, centers of ATP production, and are the site of many other important metabolic processes. An area of mitochondrial biology that is receiving increasing attention is the central role they play in maintaining cellular iron homeostasis. Iron is vital to cell survival, but its levels must be tightly regulated since mishandled iron can lead to generation of reactive

${ }^{*}$ Correspondence to: J. Timothy Greenamyre, MD, PhD, University of Pittsburgh, 3501 Fifth Avenue, Suite 7039, Pittsburgh, Pennsylvania 15260, USA. Tel.: +1 412648 9793; Fax: +1 412648 9766; E-mail: jgreena@pitt.edu. oxygen species (ROS) with deleterious consequences for the cell. Given that several neurodegenerative disorders are characterized by mitochondrial dysfunction and brain iron accumulation, understanding how mitochondria contribute to cellular iron homeostasis under physiological conditions is fundamental to understanding the complex relationships that arise in the context of aging and disease. This review focuses on how mitochondria are integrated into the molecular mechanisms of cellular iron homeostasis, highlighting recent advances in our understanding of regulation of cellular iron homeostasis and concluding with a discussion of iron dysregulation and the use of iron-directed therapies in two (AD and PD) common neurodegenerative diseases. 


\section{MITOCHONDRIA: BEYOND ENERGY PRODUCTION}

Mitochondrial oxidative phosphorylation drives a multitude of ATP-dependent cellular processes. This function is especially important in neurons, which rely heavily on oxidative phosphorylation rather than glycolysis as a source of ATP production [1]. In addition to this well-known role, mitochondria are also the site of critical metabolic and synthetic processes that are essential to cellular function and survival. Examples of such processes include: fatty acid oxidation, steroid synthesis, and synthesis of iron-sulfur clusters (ISC) and heme prosthetic groups. Moreover, as will soon be described, it is their ability to synthesize these ironcontaining prosthetic groups that positions mitochondria at the center of cellular iron homeostasis.

The ability of iron to be readily oxidized and reduced makes it ideally suited for redox catalysis. Numerous proteins in nearly all compartments of the mammalian cell - mitochondria, cytosol, nucleus, endoplasmic reticulum - require ISC and/or heme prosthetic groups to support enzymatic or structural functions (see [2] for a current list of ISC-containing proteins). Each of the following cellular processes involves ISC-containing proteins and are therefore dependent on the ability of mitochondria to synthesize ISCs: oxidative phosphorylation (complexes I-III), cellular iron homeostasis (IRP1), pyrimidine/purine metabolism, TCA cycle (mitochondrial aconitase), DNA repair (NTHL1), heme synthesis (ferrochelatase), and ISC synthesis (NBP35, CFD1) [2]. By the same token, mitochondrial impairment with dysregulation of ISC synthesis has far reaching consequences for a number of cellular processes.

The heme prosthetic group is well known for its important role in oxygen transport as a co-factor for molecules such as hemoglobin, myoglobin, and neuroglobin. Heme prosthetic groups also play catalytic roles in peroxidases and catalase $\left(\mathrm{H}_{2} \mathrm{O}_{2}\right.$ detoxification), cytochrome c (electron transport), nitric oxide generation (nitric oxide synthase), and cytochrome c oxidase (terminal step of oxidative phosphorylation) [3].

In what follows, we will discuss what is known about the uptake of iron into cells, its trafficking to mitochondria, its use in heme and ISC synthesis, and how these processes collectively contribute to proper regulation of cellular iron homeostasis. We will then examine how, in the context of neurodegeneration and mitochondrial impairment, these processes become dysregulated and lead to pathological iron accumulation.

\section{ENTRY OF IRON INTO MITOCHONDRIA}

Iron import in most cells occurs via receptormediated endocytosis following interaction between the plasma membrane protein, transferrin receptor 1 (TfR1), and the iron-carrying protein, transferrin (Tf), which binds two ferric $\left(\mathrm{Fe}^{3+}\right)$ iron ions [4] (Fig. 1). The internalized endocytotic vesicle progressively acidifies, dropping the endosomal $\mathrm{pH}$ to $\sim 6$, thereby reducing the affinity of $\mathrm{Fe}^{3+}$ for $\mathrm{Tf}$, and leading to $\mathrm{Fe}^{3+}$ release from $\mathrm{Tf}[5] . \mathrm{Fe}^{3+}$ is then reduced to $\mathrm{Fe}^{2+}$ by an endosomal membrane-bound ferric reductase, which, in developing erythrocytes, has been identified as Steap3 [6, 7]. $\mathrm{Fe}^{2+}$ is transported out of the endosome via the divalent metal transporter (DMT1) and the iron-depleted endosome then re-fuses with the plasma membrane. When the apo-Tf/TfR 1 complex encounters the $\mathrm{pH}$ of the extracellular space ( $\mathrm{pH} 7.4$ ), the affinity of apo-Tf for TfR 1 decreases and Tf is released to bind more iron, allowing the process to repeat [8].

Newly imported cellular iron has three potential fates: 1) immediate use in the cytosol in its ferrous form (e.g., as an enzyme co-factor for tyrosine hydroxylase); 2) storage in its non-bioavailable ferric form within iron-sequestering shells composed of ferritin$\mathrm{H}$ and $-\mathrm{L}$ (Ft-H/-L); or 3) delivery to mitochondria to support the many important iron-dependent functions that mitochondria perform for the cell (Fig. 1). Little is known about the mechanisms underlying the first two fates, so we will focus on how iron is delivered to mitochondria.

Given the oxidative environment of the cytosol, unregulated release of $\mathrm{Fe}^{2+}$ from the endosome into the cytosol would lead to ROS generation via Fenton chemistry and cause deleterious oxidation of cellular components. Therefore, it stands to reason that $\mathrm{Fe}^{2+}$ is protected in some manner from the cytosol prior to its uptake into mitochondria. One theory proposes that, upon release from the endosome, $\mathrm{Fe}^{2+}$ is immediately complexed by various low-molecular weight cytosolic chaperones (e.g., phosphate, citrate), which chelate the iron and preserve it temporarily until the iron or iron/chaperone complex in toto can be imported into mitochondria $[9,10]$. Shvartsman and colleagues loaded mouse cardiomyocytes with non-Tf-bound iron and showed, through the use of cellular compartmentspecific iron chelators, that mitochondrial iron uptake is not hampered [9]. They concluded that "a fraction of non-transferrin-bound iron acquired by cells reaches the mitochondria in a nonlabile form." Since non-Tfbound iron was used, the assumption is that no endoso- 


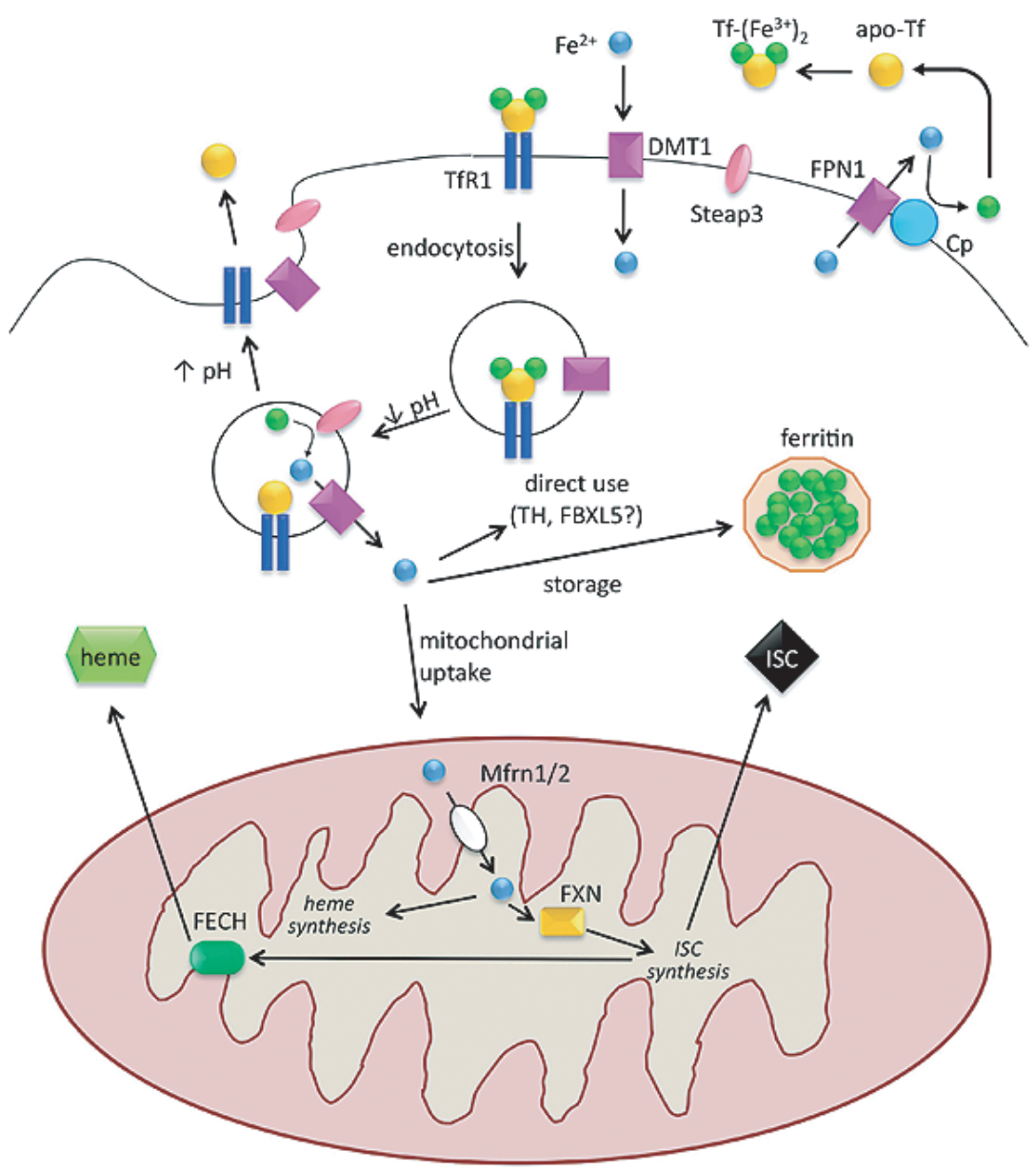

Fig. 1. Components of cellular iron homeostasis - import, storage, utilization, export - and their regulation. Endocytotic cycling of the diferric transferrin/transferrin receptor 1 complex and iron release from endosome are depicted in the top center. Upon acidification, ferrous iron released from the endosome may be: 1) used directly as a cofactor for cytosolic proteins; 2) stored in ferritin in its ferric form; or 3) imported into mitochondria. Mitochondria use iron for synthesis of iron-sulfur clusters or heme prosthetic groups, which are then distributed and utilized throughout the cell. The heme synthesis enzyme, ferrochelatase, requires an iron-sulfur cluster for its function. Ferroportin is the only known cellular iron exporter and requires the action of ceruloplasmin to oxidize the exported ferrous iron. Abbreviations: ferrous iron, $\mathrm{Fe}^{2+}$; ferric iron $\mathrm{Fe}^{3+}$; apo-transferrin, apo-Tf; diferric transferrin, Tf-( $\left.\mathrm{Fe}^{3+}\right)_{2}$; transferrin receptor 1, TfR1; divalent metal transporter, DMT1; ferroportin, FPN1; ceruloplasmin, Cp; iron-sulfur cluster, ISC; mitoferrin 1/2, Mfrn1/2; frataxin, FXN; ferrochelatase, FECH; tyrosine hydroxylase, TH.

mal vesicles are involved in the transport, leaving the possibility that chaperones chelate the incoming iron prior to its delivery to mitochondria [9]. However, it has been experimentally difficult to determine the identity of these putative iron chaperones, and the details of the "labile iron pool" remain obscure.

Another theory for how $\mathrm{Fe}^{2+}$ evades the cytosol and is delivered to mitochondria holds that endosomes containing Tf and iron transiently fuse with the mitochondrial membrane and deliver ferrous iron to unidentified mitochondrial proteins $[11,12]$. Evidence in support of this "kiss-and-run" model comes from time lapse confocal microscopy of reticulocytes (which ex- press TfR1) showing occasional co-localization of Tflabeled vesicles and labeled mitochondria [12]. Addition of non-membrane permeable iron chelators directly to the cytosol did not impair iron delivery to mitochondria as would be expected if the iron were protected from chelation by the endosome [12]. However, specific molecules involved in the purported endosomemitochondrion "kiss" remain to be identified.

It is likely that mechanisms of mitochondrial iron delivery are cell-type specific. As an example of this, Mastroberardino and colleagues showed that TfR2, a TfR isoform that is expressed mainly on hepatocytes, is also expressed on nigral dopamine neurons and me- 
diates iron import into the cell and mitochondria [13]. Interestingly, the authors found that TfR2 contains a previously undescribed functional mitochondrial targeting sequence which accounts for the observed in $v i$ vo localization of TfR2 to both the plasma membrane and mitochondrial inner membrane of nigral dopamine neurons [13]. Furthermore, they demonstrated that expression of TfR2 is sufficient to bring iron into mitochondria in vitro, by heterologous expression of TfR2, adding $\left[{ }^{59} \mathrm{Fe}\right]$-loaded $\mathrm{Tf}$ to the culture media, and assessing levels of the radioisotope in purified mitochondria [13]. Iron uptake into mitochondria was decreased following TfR2 silencing in this system [13]. Further studies are required to determine mechanistically how TfR2 functions in mitochondria to promote iron import.

While each of these mechanisms accounts for iron delivery to mitochondria, none of them explains how iron actually enters the mitochondrial matrix, where it is utilized for prosthetic group synthesis. Mitoferrins (Mfrn) are transporters located on the mitochondrial inner membrane of mammalian cells that bring $\mathrm{Fe}^{2+}$ from the intermembrane space to the matrix [14]. Whereas Mfrn2 is expressed ubiquitously, Mfrn1 displays a more restricted pattern of tissue expression in mammals, with highest levels in hematopoietic tissues spleen, bone marrow, and fetal liver [14]. Mfrn1 and Mfrn2 appear to be redundant in non-erythroid cells, while Mfrn1 is critical to mitochondrial iron uptake in developing erythroid cells [15]. The mitochondrial inner membrane-bound ATP-binding cassette transporter Abcb10 was recently shown to stabilize Mfrn1 protein through physical interaction, prolonging its halflife and allowing sustained mitochondrial iron uptake to meet the staggering demands of hemoglobin synthesis in developing erythrocytes [16]. When heme levels are high, Abcb10 is down-regulated, leading to Mfrn1 destabilization, and decreased mitochondrial iron uptake [16]. It remains unclear what regulates Mfrn2 in the majority of tissues. However, it is interesting to note that overexpression of Mfrn1/2 does not lead to greater mitochondrial iron loading, suggesting that regulatory mechanisms can override the mitoferrins to prevent excessive mitochondrial iron loading [15]. These regulatory mechanisms and the players involved require further investigation.

\section{UTILIZATION OF IRON WITHIN MITOCHONDRIA}

Following transport of $\mathrm{Fe}^{2+}$ into the matrix, it can either be used in the synthesis of prosthetic groups
(ISCs or heme) or stored within the mitochondria. We will briefly present both synthetic processes in order to introduce key molecules, which are sites of regulation (and dysregulation). For excellent, detailed reviews of ISC and heme synthesis, we refer readers to $[2,17,18]$.

\section{Iron-sulfur cluster synthesis}

As mentioned above, ISC-containing proteins play active roles in essential processes in nearly all compartments of the cell. Much of our knowledge about ISC synthesis comes from studies in lower organisms (bacteria and yeast), but studies in mammals have shown that there is a high degree of conservation [19]. ISC synthesis occurs in mitochondria, but proper transport to and insertion into target apo-proteins requires a host of other proteins in other subcellular compartments. Three general systems are vital to ISC synthesis: 1) mitochondrial ISC assembly; 2) mitochondrial export machinery; and 3) cytosolic ISC assembly. To avoid degradation, [2Fe-2S] clusters are first assembled on a protein scaffold consisting of an ISCU homodimer [2]. $\mathrm{Fe}^{2+}$ is thought to be donated to the scaffold by frataxin and the sulfur is derived from cysteine via Nfs1/ISD11 complex-mediated desulfuration [2]. Once completed, the ISC is shuttled to its mitochondrial target apo-proteins by chaperones, including glutaredoxin 5 (Grx5), in a process that is still incompletely understood [20,21]. However, there is evidence that chaperones specific for certain apo-proteins exist. For example, Ind1 is necessary for insertion of ISCs into Complex I of the electron transport chain, which contains 8 ISCs [22,23].

It remains unclear how ISCs are exported from mitochondria to the cytosol and whether, in fact, they are exported as ISCs or in some other intermediate form. Evidence supports a role for the ATP binding cassette transporter, Abcb7, in the export of ISC intermediates from mitochondria to the cytosol, though there may be interaction partners that help mediate export [24,25]. Given the labile nature of ISCs, chaperones are required to receive the ISCs in the cytosol and protect them from degradation. Glutathione in its reduced form (GSH) has been implicated in this role, though chaperones may also be involved [19]. In the cytosol, a protein scaffold consisting of Nbp35 (NUBP1) and Cfd1 (NUBP2) is employed to construct ISCs using ISC components that have been exported from mitochondria [2]. Nar1 and its interaction partner, Cia1, are involved in shuttling the ISC to apo-proteins within the cytosol [2]. Other chaperones are likely involved in ISC delivery within the nucleus or endoplasmic reticulum. 


\section{Heme synthesis}

Heme synthesis requires concerted reactions in both the mitochondria and cytosol. In the first and rate-limiting step of heme synthesis, aminolevulinic acid synthase (ALAS1/2) catalyzes the production of aminolevulinic acid from glycine and succinylCoA [18]. ALAS1 is expressed ubiquitously whereas ALAS2 (also known as eALAS) is expressed only in immature erythrocytes and contains an iron response element (IRE) in the 5' UTR of its transcript, allowing its levels to increase when iron is abundant [18]. Aminolevulinic acid is exported to the cytosol through an unknown mechanism where it is then elaborated into coproporphyrinogen III in four successive enzymecatalyzed reactions [18]. Coproporphyrinogen III is imported back into the mitochondria, converted to protoporphyrinogen IX in the mitochondrial intermembrane space by coproporphyrinogen oxidase, and subsequently imported into the matrix by the ATP binding cassette transporter, Abcb6 [18,26]. Within the matrix, it is converted into protoporphyrin IX by protoporphyrinogen oxidase and becomes heme upon assimilation of $\mathrm{Fe}^{2+}$, which is catalyzed by ferrochelatase [18].

In the process of discovering members of the ISC pathway, it was found that deletion or silencing of various genes involved in ISC synthesis often produces a phenotype of anemia (via suppression of heme synthesis) and mitochondrial iron overload in cell and animal models, as well as in humans [2,27,28]. Deletion or silencing of components of the heme synthesis pathway instead often results in porphyria-suppression of heme synthesis with toxic accumulation of heme intermediates - yet normal ISC synthesis [18]. This discrepancy may be explained by the fact that the heme synthesis enzyme, ferrochelatase, requires a $[2 \mathrm{Fe}-2 \mathrm{~S}]$ cluster for its stability [29,30]. When ISC synthesis is impaired, apo-ferrochelatase is unstable and degrades, rendering heme synthesis incomplete at the final step [31]. Therefore, in order to successfully synthesize heme, cells must ensure that ISC synthesis is operational.

Erythroid precursors possess another level of heme regulation that ties heme synthesis to successful ISC synthesis. Whereas ferrochelatase protein levels are directly affected by ISC deficiency, the erythroid-specific heme synthesis enzyme, ALAS2, is indirectly affected by ISC deficiency: decreased ISC synthesis leads to increased IRE-binding activity of IRP1 and subsequent post-transcriptional down-regulation of ALAS2 through its 5' UTR IRE.
Nilsson and colleagues used large-scale in silico expression screening followed by in vivo validation in zebrafish to identify candidate mitochondrial transporters and regulators involved in heme synthesis [32]. They reasoned that, if genes are co-regulated, then their expression levels should correlate. In addition to finding three putative mitochondrial transporters (SLC25A39, SLC22A4, TMEM14C), they also identified two genes known to be involved in ISC synthesis (C1orf69, ISCA1) [32]. The fact that expression levels of these genes correlate with expression levels of heme synthesis genes indicates that in addition to the ISC and heme synthesis pathways intersecting, they also may be co-regulated.

\section{Iron storage in mitochondria}

Mitochondria, by virtue of physiological electron leak during oxidative phosphorylation, are a principal site of cellular ROS production [33-35]. Several enzymatic defenses are in place in mitochondria to detoxify these ROS before they can damage key proteins, lipids, and nucleic acids [36]. Since mitochondria require a steady influx of $\mathrm{Fe}^{2+}$ to feed ISC and heme synthesis pathways, there is a possibility of further ROS generation through Fenton chemistry. To avoid this, mitochondria have two options: either immediately use the $\mathrm{Fe}^{2+}$ in a synthetic pathway or sequester it in a storage protein complex consisting of oligomerized mitochondrial ferritin (FtMt). The sequence of this nuclearencoded iron storage protein is highly similar to that of the cytosolic ferritin, Ft-H, yet it also possesses an Nterminal mitochondrial targeting sequence [37]. Like $\mathrm{Ft}-\mathrm{H}$, FtMt oligomerizes to form a shell with ferroxidase centers that oxidize $\mathrm{Fe}^{2+}$ to the less redox-active $\mathrm{Fe}^{3+}$ and sequester it from reactive molecules within the matrix.

Immunohistochemical characterization of FtMt expression in the normal adult mouse revealed that it is expressed in cells with great demands for oxidative phosphorylation, such as brain (neurons), testis, pancreatic islet cells, and cardiomyocytes [38]. Unlike many iron-related genes, FtMt does not possess an IRE, and little is known about the mechanisms that regulate FtMt expression. FtMt expression is detected in ringed sideroblasts (peri-nuclear iron-laden mitochondria within immature erythrocytes) in human sideroblastic anemias, but not in healthy erythroblast mitochondria [39], indicating that FtMt is either upregulated as a compensatory response in disease states or is 
aberrantly upregulated and draws increasing amounts of iron into mitochondria.

Transient over-expression of FtMt in a human cell line lowered ROS production following treatment with $\mathrm{H}_{2} \mathrm{O}_{2}$ and enhanced cell viability, suggesting that FtMt functions as an anti-oxidant by sequestering reactive $\mathrm{Fe}^{2+}$ before it can catalyze ROS generation [40]. When FtMt was transiently overexpressed in fibroblasts from patients with Freidriech's ataxia (FRDA), which express low levels of frataxin, they were also protected against oxidative insult and the activities of various ISC-containing enzymes were restored [40]. Interestingly, overexpression of FtMt in a human lung cancer cell line caused depletion of cytosolic iron and mitochondrial iron loading with the expected downstream consequences for cellular iron homeostasis: increased iron uptake through TfR1 upregulation and decreased iron storage through $\mathrm{Ft}-\mathrm{H} / \mathrm{-L}$ down-regulation [41]. It remains unclear whether this shunting of iron from cytosolic Ft to FtMt is relevant to in vivo iron regulation and what mechanism underlies this phenomenon. In contrast to studies showing an apparent antioxidant effect of FtMt, application of pro-oxidants to cells expressing FtMt under an inducible promoter was found to enhance ROS production and cell death as compared to cells not expressing FtMt [42]. However, this was not observed following application of the pro-oxidant 6hydroxydopamine (6-OHDA) to an SH-SY5Y (human dopaminergic) cell line that stably expresses FtMt [43]. Instead, these authors found that FtMt expression attenuated 6-OHDA-induced cell death, ROS production, and increases in intracellular calcium [43].

Frataxin, the mitochondrial matrix protein whose deficiency causes FRDA, is thought to deliver iron to the ISC synthesis machinery [44]. Some studies on the yeast frataxin homologue, Yfh1, suggest that it may also serve as a mitochondrial antioxidant by oligomerizing and sequestering excess iron [45]. However, yeast expressing a mutant Yfh1 that fails to oligomerize are phenotypically normal, suggesting that Yfh1 is not critical to iron storage [46]. Evidence for frataxin possessing an iron-storage function in mammalian cells is lacking.

\section{CELLULAR IRON HOMEOSTASIS: THE IRP SYSTEM}

Mammals differ markedly from yeast and bacteria in the way they regulate cellular iron homeostasis. Whereas yeast and bacteria regulate levels of iron-related pro- teins at the transcriptional level through an "iron regulon" [19,47], mammals utilize a post-transcriptional mechanism to coordinately regulate the expression of various transcripts involved in iron import, storage, utilization, and export [48]. Multiple genes that are involved in each of these processes contain iron regulatory element (IRE) stem loops in either the 3'- or 5'untranslated regions (UTR) of their mRNA. These IREs can be bound by either of two cytosolic iron regulatory proteins (IRP1/2), which provide steric hindrance to either ribosomal machinery (when bound to 5' UTR IREs) or exonucleases (when bound to 3' UTR IREs) (Fig. 2A). Therefore, there is a functional significance to the IREs being distributed to either the 5' or 3' UTRs of particular transcripts: when an IRP is bound to the 5' UTR the transcript is not translated and when bound to the 3' UTR the transcript is not degraded. In this way, it allows for correction of cellular iron levels under conditions of both too much iron and too little. To date, 9 IRE-containing transcripts have been identified and validated. These genes play roles in iron import (TfR1, DMT1+IRE), iron storage (Ft-H/-L), iron export (ferroportin), hypoxic response/erythropoiesis (HIF $2 \alpha)$, the tricarboxylic acid cycle (mt-aconitase), erythroid heme synthesis (eALAS), and cell cycle regulation (CDC14A).

Genes important for iron storage (Ft-H, Ft-L) and export (ferroportin) contain 5' UTR IREs, and are thus down-regulated when cellular iron levels are low. Such down-regulation prevents the sequestration and export of iron under iron-deficient conditions, increasing the pool of bioavailable iron within the cell. Genes important for iron import (TfR1) and vesicular release (some forms of DMT1) contain 3' UTR IREs and are consequently upregulated when cellular iron levels are low, thus correcting the cellular iron deficiency. Putative IREs have been discovered in the 5' UTRs of amyloid$\beta$ protein precursor (A $\beta \mathrm{PP}$ ) [49] and $\alpha$-synuclein [50]; however, in vivo evaluation of these IREs must be performed before they can join the ranks of other bona fide IRP-regulated transcripts.

IRP1 and IRP2 are functionally similar cytosolic proteins that bind the same consensus IRE with equal affinity [51]. They are co-expressed in most mammalian tissues, and owing to their different structures, they are regulated differently [52]. IRP1 is an ISC-containing protein with two mutually exclusive functions that depend upon whether its ISC is intact. An intact ISC causes IRP1 to assume a conformation that allows it to act as a cytosolic aconitase, interconverting citrate and isocitrate [53] (Fig. 2B). The absence of an intact 

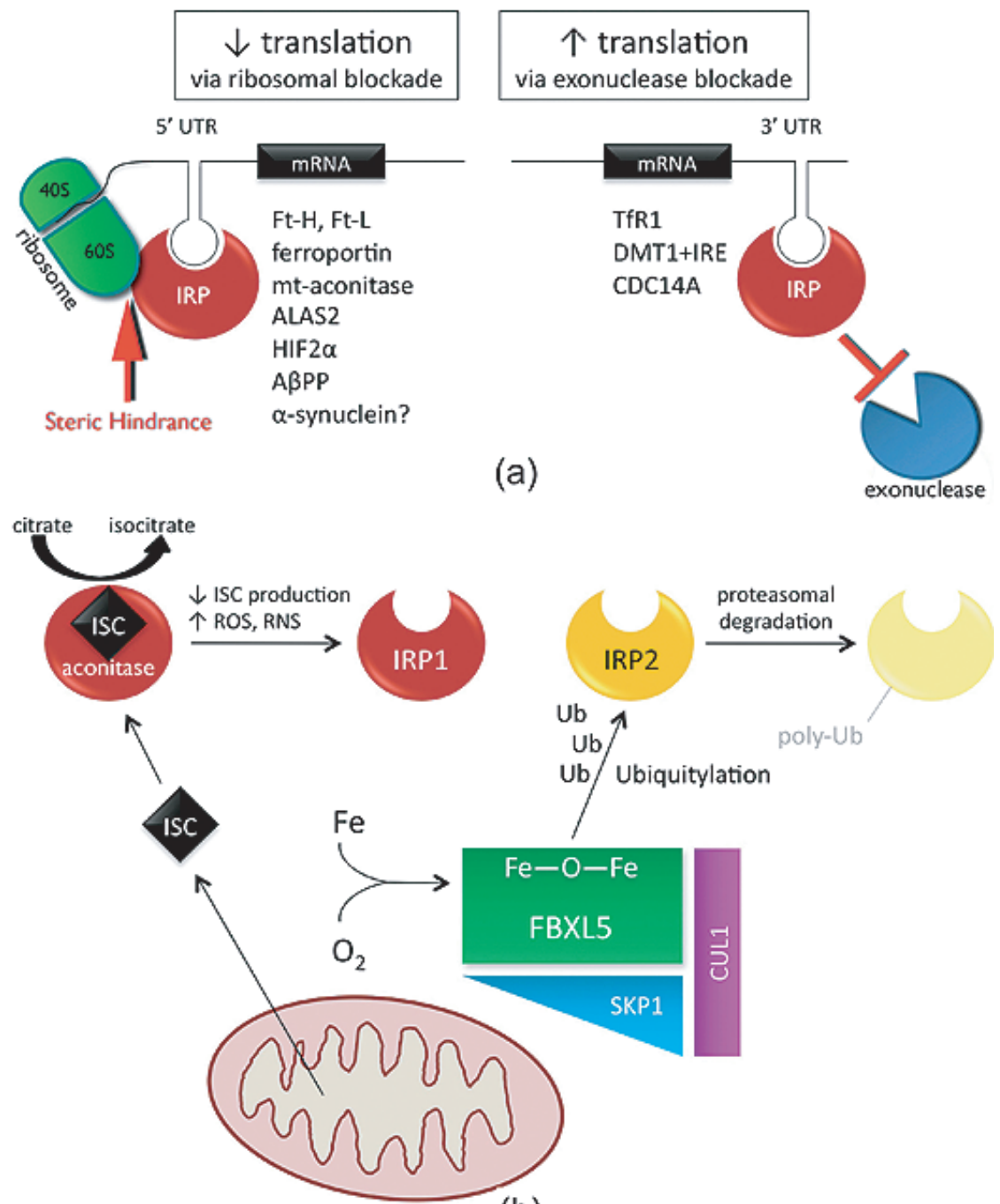

poly-Ub

(b)

Fig. 2. Iron regulatory proteins control cellular iron homeostasis. A) Transcripts containing iron-regulatory elements (IREs) in either their 5 , or 3' untranslated regions (UTR) are bound by iron regulatory proteins (IRP) when iron levels are perceived to be low. IRP binding to 5' IREs provides steric hindrance to ribosomal machinery, leading to decreased translation of the transcript. IRP binding to 3' IREs blocks the action of exonucleases, thereby protecting the transcripts from degradation and increasing translation. Transcripts that contain IREs in either their 5' or 3' UTRs are listed. Note: There are four isoforms of DMT1 mRNA, only some of which contain 3' UTR IREs. Abbreviations: ferritin-H/-L, Ft-H/-L; mitochondrial aconitase, mt-aconitase; aminolevulinic acid synthase 2, ALAS2; hypoxia inducible factor $2 \alpha$, HIF2 $\alpha$; amyloid $\beta$ precursor protein, $\mathrm{A} \beta \mathrm{PP}$; transferrin receptor 1, TfR1; divalent metal transporter with IRE, DMT1+IRE; cell division cycle 14 homolog A, CDC14A. B) When it contains a functional ISC, IRP1 (red) functions as a cytosolic aconitase (converting citrate to isocitrate); in the absence of a functional ISC it is converted to an IRE-binding protein. The status of the ISC can change in response to decreased ISC production or increased ISC disruption by reactive oxygen species (ROS). IRP2 (yellow) is a constitutive IRE-binding protein that is regulated by proteasomal degradation. When cellular iron and oxygen levels are adequate, FBXL5 (green) can complex with SKP1 (blue) and CUL1 (purple) to form a functional E3 ubiquitin ligase that tags IRP2 for degradation (light yellow).

ISC, due to either oxidative disruption of the ISC or decreased ISC synthesis, causes IRP1 to assume a conformation that confers IRE-binding activity [54,55]. IRP2 lacks an ISC and is instead constitutively active as an IRE-binding protein; it is regulated by proteasomal degradation, as we will describe shortly.
The relative contribution of each IRP to cellular iron homeostasis in vivo has been elucidated in vivo through the use of knockout mice. IRP1 ${ }^{-/-}$mice display a remarkably mild phenotype with mild iron dysregulation only in tissues where IRP1 expression is substantially greater than IRP2 [56]. This observation suggested 
that IRP1 and IRP2 may be redundant and can compensate for each other's loss. However, knocking out IRP2 in vivo revealed that this is not the case. The IRP2 KO mouse displays a phenotype of microcytic anemia, cerebellar and striatal iron accumulation, age-related neurodegeneration, and motor deficits [57,58]. This finding supports the notion that IRP2 is the main regulator of cellular iron homeostasis in vivo. The explanation for why IRP1 seems to contribute little to in vivo cellular iron homeostasis was examined by incubating cells under different tensions of oxygen - from 3-4\% (the typical range of most tissues) to $21 \%$ (ambient conditions in which most in vitro experiments are performed) - and assessing the relative IRE-binding activity versus aconitase activity of IRP1 [59]. Under low oxygen tensions, the ISC of IRP1 is intact, preventing it from binding IREs and rendering it a cytosolic aconitase [59]. Additional in vivo support for this notion came from experiments in which IRP $2^{-/}-$mice were administered TEMPOL, a drug that disrupts ISCs [60]. The investigators found that TEMPOL treatment led to increased IRE-binding activity along with decreased aconitase activity of IRP1 and conferred neuroprotection to the IRP2 ${ }^{-/-}$mice relative to vehicle-treated IRP2 ${ }^{-/-}$mice [60].

IRP2 regulation was poorly understood until quite recently, when two groups independently discovered an iron- and oxygen-sensing protein called FBXL5, which complexes with other proteins (SKP1, CUL1) to form an E3 ubiquitin ligase that marks both IRP1 and IRP2 for proteasomal degradation [61,62] (Fig. 2B). FBXL5 stability depends upon an evolutionarily conserved hemerythrin-like domain that binds iron and oxygen $[61,62]$. When iron or oxygen levels are low, the hemerythrin-like domain cannot form and the protein itself is consequently targeted for proteasomal degradation [61,62]. As a result, the E3 ubiquitin ligase complex is incomplete and cannot target IRPs for degradation; IRP levels consequently remain high. This leads to increased IRE-binding and the downstream effect of enhanced cellular iron uptake. While IRP1 is known to be regulated through its ISC (see above), the ability of the FBXL5-containing E3 ubiquitin ligase to ubiquitylate IRP1 [62] possibly adds another level of regulation. It has been hypothesized that when its ISC is intact, IRP1 assumes a conformation that allows it to evade ubiquitylation by this complex, but further experiments are required to prove that this is so [63].

\section{MITOCHONDRIA AND CELLULAR IRON SENSING}

As we have described, the IRE-binding activity of IRP1 is regulated by the presence or absence of an ISC. Therefore, insofar as they produce ISCs, mitochondria play a central role in coordinating cellular iron homeostasis (iron import, utilization, storage, and export). Thus, cellular iron sensing (through ISCs) is a functional determination that reflects the ability of mitochondria to synthesize ISCs. If a halt in ISC production occurs as a result of lack of iron, then the cell responds properly, through IRP1-mediated post-transcriptional regulation, by importing more iron. However, if ISC levels are depleted due to either mitochondrial dysfunction (e.g., defects in the ISC synthesis/incorporation pathway) or direct disruption of ISCs by ROS, then iron uptake is enhanced in the same manner yet the cellular response of importing more iron is maladaptive since it can lead to further generation of ROS.

If the iron that composes the hemerythrin-like domain of FBXL5 is derived directly from the cytosol (and not from an ISC), then it would mean that FBXL5mediated regulation of IRPs can occur independently of mitochondrial ISC production. Thus, FBXL5 may be a way for cells to sense cytosolic iron, regardless of whether mitochondria are properly synthesizing ISCs. Determining whether this is the case requires further investigation.

\section{BRAIN IRON HOMEOSTASIS}

Iron is critical to both neurodevelopment and normal function of the adult brain. Within the adult brain, the basal ganglia are particularly rich in iron, and it is therefore not surprising that several diseases of the basal ganglia lead to iron dysregulation [64]. An important caveat when considering iron regulation in the brain is that most of our knowledge about the mechanisms of iron homeostasis comes from studies that have been performed in peripheral cell types, especially in developing erythrocytes. The majority of iron homeostasis proteins that have been characterized in the periphery are also present in brain. However, given the regional, cellular, and functional non-uniformity of the brain, it may be the case that these same proteins are utilized differently in the central nervous system to achieve brain iron homeostasis. Before turning to the topic of brain iron dysregulation in the context of neurodegeneration, it will be useful to briefly introduce the roles that var- 
ious cells within the brain are thought to play in iron homeostasis.

Iron can be histochemically localized to every cell type in the brain; under normal conditions it is present most abundantly in oligodendrocytes, but is also found in neurons, astrocytes, and microglia [65]. The distribution of iron homeostasis proteins in the brain helps reveal the dynamics of brain iron homeostasis among various cell types. Whereas the source of $\mathrm{Tf}$ in the periphery is the liver, oligodendrocytes are believed to be the primary source of $\mathrm{Tf}$ in the brain based on in situ hybridization studies, though neurons in some brain regions may also contribute to the available pool of Tf. By binding $\mathrm{Fe}^{3+}$ with high affinity, Tf not only limits the amount of potentially redox-active free iron in the extracellular space, but also provides a source of iron for TfR-mediated uptake by various cells. Furthermore, oligodendrocytes are critical for axon myelination, and this process is iron-dependent [66].

In the periphery, systemic iron homeostasis is controlled by signaling between the liver-derived peptide hormone, hepcidin, and its receptor, the iron exporter ferroportin. When the liver senses high blood iron levels, it responds by increasing production and release of hepcidin. Hepcidin acts principally on the duodenum and spleen, where it binds and down-regulates ferroportin, thus limiting the entry into the blood of iron derived from the diet or phagocytosis of senescent erythrocytes, respectively. When the liver senses low blood iron levels, it down-regulates hepcidin expression, indirectly allowing iron to enter the blood from the duodenum and spleen by sparing ferroportin. Given the permeability restrictions that the blood-brain barrier (BBB) imposes, it is unlikely that liver-derived hepcidin regulates iron homeostasis within the brain. In the adult mouse brain, hepcidin mRNA is widely distributed and hepcidin protein can be detected in both neurons and astrocytes [67,68]. Ferroportin is likewise diffusely expressed throughout the brain and is present on all cell types, including endothelial cells and ependymal cells in the choroid plexi [69]. Therefore, it does not appear that iron sensing in the brain is centralized as it is in the periphery; it may be the case that iron sensing and consequent hepcidin release is a local phenomenon in brain. What bearing this may have on disease pathogenesis is unexplored at this point.

\section{BRAIN IRON DYSREGULATION AND NEURODEGENERATION}

Neurodegeneration represents the intersection of many conditions that are known individually to affect iron homeostasis. These include: aging, mitochondrial dysfunction, oxidative stress, neuroinflammation, and additional features of disease pathophysiology (e.g., protein aggregation). As such, except in genetic disorders, it is difficult to attribute iron dysregulation to a single pathogenic mechanism. Because of this interaction of several factors, it is of prime importance to understand mechanistically how iron is being dysregulated in each disorder so that it can be appropriately ameliorated through therapeutic intervention.

The basal ganglia are relatively iron-enriched regions and are often areas of pathological brain iron accumulation in neurodegenerative disease [65,70,71]. Iron accumulates in healthy brains as a result of normal aging [65]. A question that frequently arises in the study of neurodegenerative disorders is whether a pathological phenomenon contributes to disease or occurs secondary to the main disease process. In this context, it is of interest to know whether brain iron dysregulation contributes to neurodegeneration or occurs as a result of neurodegeneration. The answer is probably both. Many neurodegenerative diseases are associated with accumulation of iron in the central nervous system. While some of these diseases are due to a primary defect in iron-related genes - e.g., neuroferritinopathy (Ft-L), aceruloplasminemia (ceruloplasmin), pantothenate kinase-associated degeneration (PANK2) - most have iron dysregulation as a secondary feature [70]. Nonetheless, it is established that excessive cellular iron is harmful to cells and promotes ROS formation through Fenton chemistry. While the BBB serves to limit intrusion of various substances, including iron, into the brain, in the context of disease, the integrity of the BBB may be compromised, allowing excessive, unregulated influx of iron.

As discussed, mitochondria play a crucial role in regulating cellular iron homeostasis. The fact that these organelles are impaired in neurodegenerative diseases raises the possibility that their dysfunction may lead to iron dysregulation, which may, in turn, lead to further mitochondrial dysfunction. We will discuss the current understanding of iron accumulation in two common neurodegenerative diseases - Alzheimer's disease and Parkinson's disease - and review the results of iron chelation therapy in each.

\section{ALZHEIMER'S DISEASE}

Alzheimer's disease (AD) is characterized by the progressive dysfunction and degeneration of neurons 


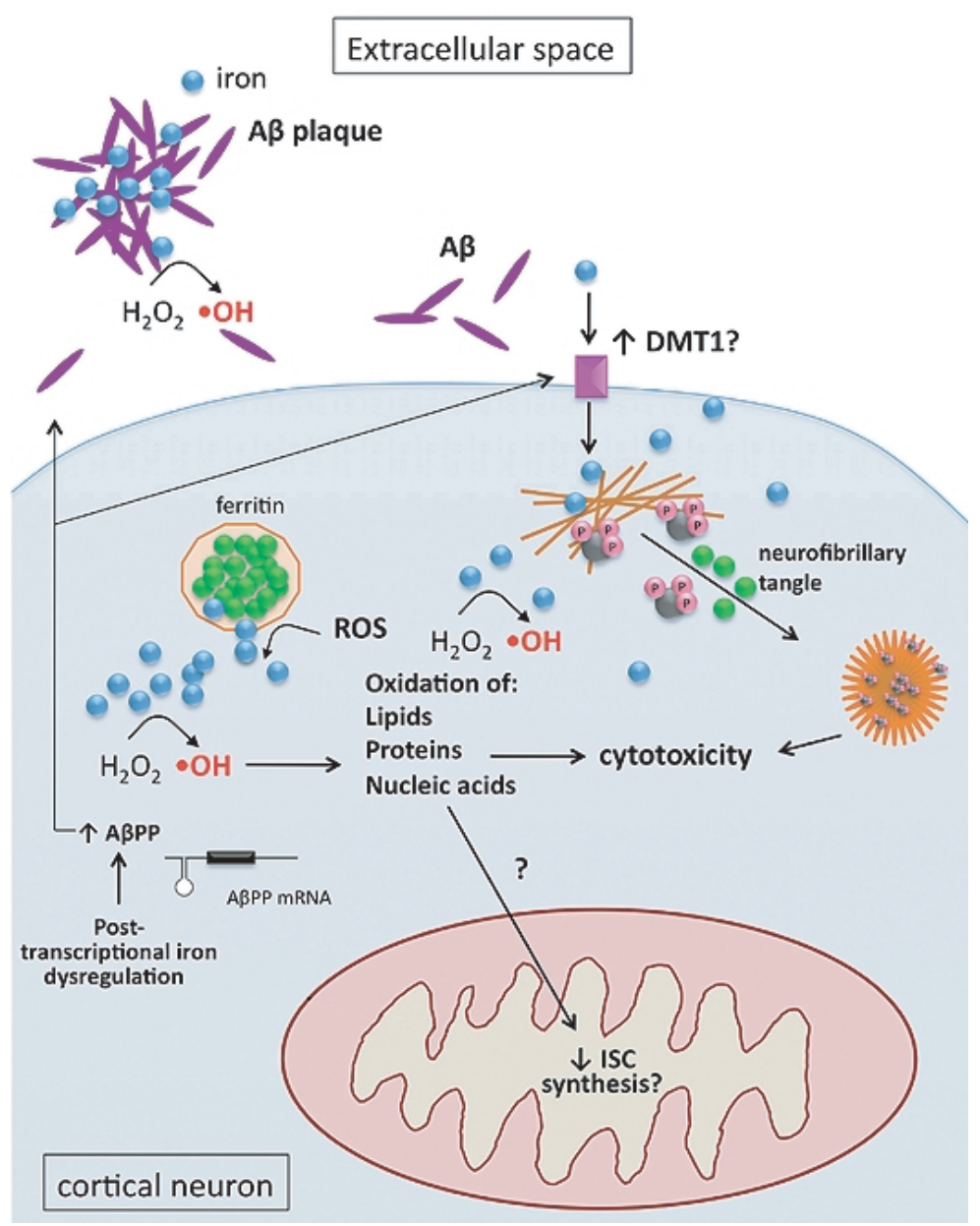

Fig. 3. Iron dysregulation in Alzheimer's disease. Subcellular iron-related pathology in cortical neurons includes: Fenton chemistry (hydroxyl radical formation, $\cdot \mathrm{OH}$ ); interaction of iron (blue) with $\mathrm{A} \beta$ (purple) in the extracellular space; iron-induced (green) aggregation of hyper-phosphorylated (pink) tau (black) and neurofibrillary tangle formation; increased expression of DMT1; increased A $\beta$ production, with possible contribution from IRP dysregulation.

in various cortical regions, which leads to progressive memory loss and dementia [72]. Within the AD brain, extracellular, proteinaceous plaques containing aggregated amyloid- $\beta$ peptide $(\mathrm{A} \beta)$ and intracellular, hyper-phosphorylated aggregates of the microtubuleassociated protein tau, called neurofibrillary tangles (NFTs), form around and within neurons in the dysfunctional brain regions [72]. In addition to these characteristic features, the $\mathrm{AD}$ brain has been found to contain increased levels of various metals: iron, copper, zinc, and aluminum [73]. Pathological levels of iron are found in association with $\mathrm{A} \beta$ in the extracellular space [74], as well as within neurons containing NFTs [75] (Fig. 3). There is evidence that iron accumulation in affected regions of the AD brain may outstrip the ability of Ft to safely sequester it, which would lead to pathologic ROS formation through Fenton chemistry [76]. Indeed, oxidative stress is a welldocumented feature of $\mathrm{AD}$ and there is evidence to support that iron contributes to oxidative stress in $\mathrm{AD}$, as it does in other neurodegenerative diseases [77].

Iron also plays a role in the development of the two pathological hallmarks of $\mathrm{AD}$, amyloid plaques and NFTs. Amyloid plaques are composed of $\mathrm{A} \beta$, which is processed from $\mathrm{A} \beta$ protein precursor $(\mathrm{A} \beta \mathrm{PP})$ by $\gamma-$ secretases. $\mathrm{A} \beta$ is a metalloprotein that has been shown to bind iron as well as other metals [78]. While some researchers have proposed that iron-binding by $\mathrm{A} \beta$ is a protective response to sequester iron and prevent the development of oxidative stress [79], iron binding has also been shown to promote $\mathrm{A} \beta$ aggregation and neurotoxicity $[77,80]$. Similar to its effect on $\mathrm{A} \beta$, ferric 
iron has been shown to induce the aggregation of hyperphosphorylated tau, leading to the deposition of NFTs, the other pathological hallmark of AD [81] (Fig. 3).

Beyond its contribution to the development of amyloid plaques and NFTs, iron dysregulation may alter $\mathrm{A} \beta \mathrm{PP}$ metabolism at the post-transcriptional level. It was recently found that the $\mathrm{A} \beta \mathrm{PP}$ transcript contains an atypical IRE in its 5' UTR, and in vitro work has demonstrated that it is a functional IRE [49]. Because the IRE is in the 5' UTR, increased iron levels should lead to increased protein levels of $\mathrm{A} \beta \mathrm{PP}$, and after processing, to increased protein levels of $\mathrm{A} \beta$ and increased $\mathrm{A} \beta$ aggregation. Thus, iron may be acting both directly and indirectly to promote the development of amyloid plaques in $\mathrm{AD}$.

The issue of how iron levels become elevated in $\mathrm{AD}$ remains unresolved, but iron may be dysregulated, in part, secondary to expression changes in some ironrelevant genes. Zheng and colleagues recently reported in a neuronal cell line that stable overexpression of the human $\mathrm{A} \beta \mathrm{PP}$ Swedish mutation led to increases in DMT1 and that silencing of DMT1 in these cells led to a reduction in $\mathrm{A} \beta \mathrm{PP}$ mRNA and subsequent $\mathrm{A} \beta$ formation [82]. They also claimed that two isoforms of DMT1 message (with and without the 3' UTR IRE) are increased in a transgenic mouse model of AD [82]. Confirmation in human postmortem tissue will be necessary before these findings can be generalized and specific gene dysfunction targeted for therapeutic restoration.

Given that various metals have been found to accumulate and play a toxic role in $\mathrm{AD}$ progression, ironchelation is a potential therapeutic intervention. A small study found that intramuscular administration of the iron chelator, desferrioxamine (DFO), to patients with suspected $\mathrm{AD}$ slowed the rate of decline of daily living skills as compared to patients treated with placebo [83]. Administration of the chelator, clioquinol (CQ), to APP2576 transgenic mice led to a robust decrease in brain $\mathrm{A} \beta$ deposition [84]. A small pilot Phase II clinical trial using CQ in AD patients found a slowed decline in cognitive performance in patients with severe $\mathrm{AD}$ as compared to placebo-treated patients with equally severe $\mathrm{AD}$ [85]. A related 8-hydroxy quinoline analog with better BBB penetration, PBT2, was shown to be neuroprotective in two transgenic mouse models of $\mathrm{AD}$ [86]. While a host of iron-chelating drugs are already FDA-approved and have been shown to be efficacious to varying degrees [79], other investigators have focused their attention on the 5' UTR IRE of $\mathrm{A} \beta \mathrm{PP}$ and have screened multi-functional drugs (such as M30, VK28, HLA20, and ECGC) for their ability to suppress the IRE in an attempt to prevent ironassociated increases in A $\beta$ PP [87-89]. Indeed, these drugs may prove superior to standard iron chelators in that they appear to target iron-related AD pathology on multiple levels. Of course, more extensive pre-clinical and clinical testing will be necessary before conclusions about their efficacy in modifying AD progression can be made.

\section{PARKINSON'S DISEASE}

Iron accumulation in the substantia nigra (SN) has been recognized as a pathological feature of PD for more than 80 years, pre-dating even the discovery of dopamine in the brain [90]. In recent years, the reproducible accumulation of iron within the SN has prompted much interest in in vivo diagnostic imaging in suspected PD patients [91,92]. The degree of iron accumulation and location of primary accumulation have been issues of debate. Quantification of nigral iron is highly technique-dependent, and certain methods of tissue preparation or storage can artifactually alter nigral iron content [93]. Even if iron levels in the parkinsonian SN are only slightly higher (1.5- to 2-fold) than age-matched normal brains, as detected in nigral homogenates, this small absolute difference may make a significant contribution to ROS generation through Fenton chemistry. The inability to quantify iron within specific cell types when using nigral homogenates is also a caveat in interpreting reports of no change in nigral iron content; increases within certain cell types may contribute to $\mathrm{PD}$ progression even in the absence of gross changes in tissue iron content. Also, many methods for assessing iron are limited in their ability to distinguish between redox-active (e.g., weaklybound ferrous iron) and redox-inactive (e.g., Ft-bound) iron, thus further complicating interpretation of some studies.

There is also ongoing debate as to where iron initially accumulates (Fig. 4A). Postmortem examination of the PD brain reveals that much of the iron is present in nigral microglia rather than nigral dopamine neurons [94], although increased iron levels have been identified within human nigral dopamine neurons as well $[95,96]$. Given the fact that most of these brains come from patients who died with end-stage PD, it cannot be determined whether the initial site of iron accumulation is indeed in microglia or whether microglia 


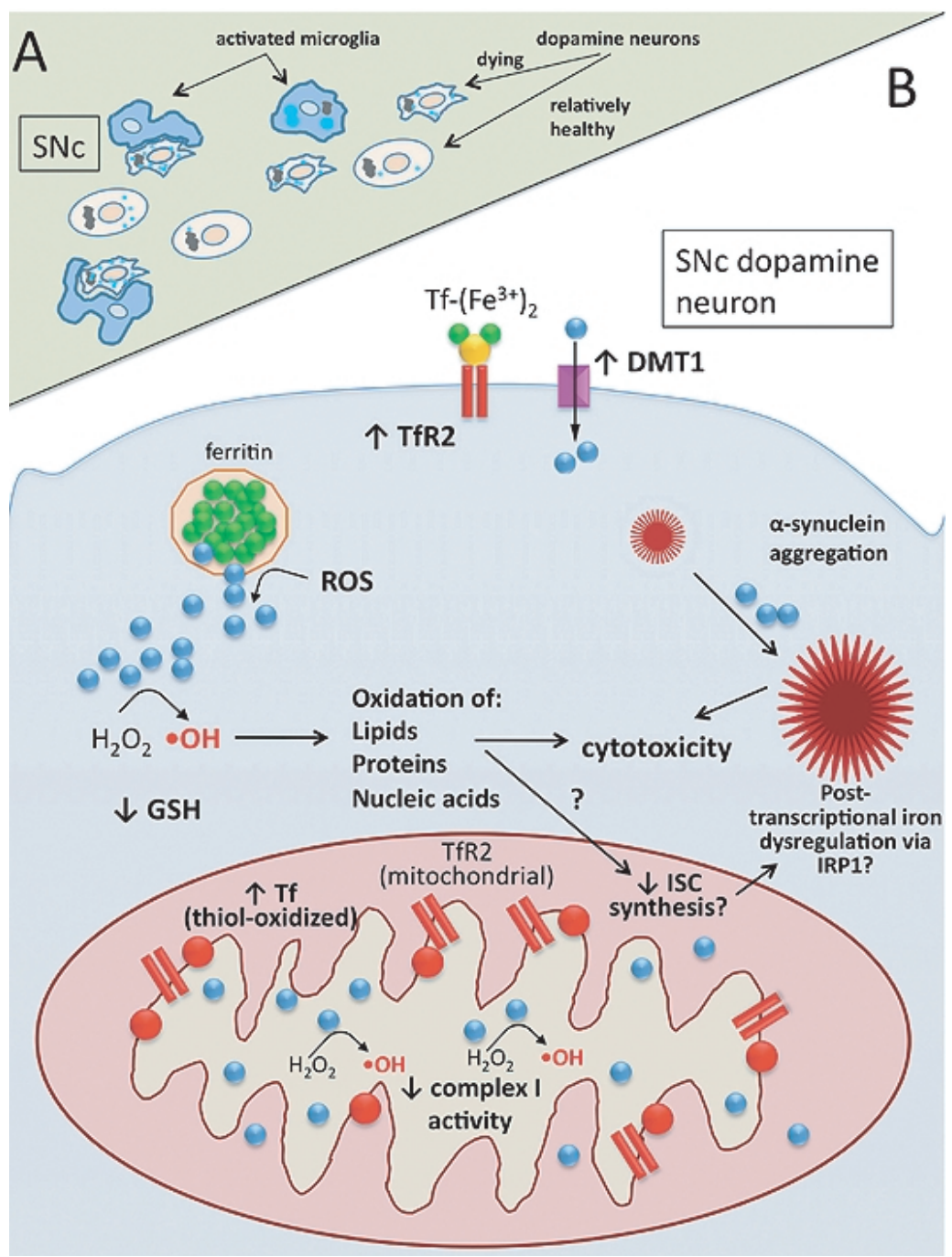

Fig. 4. Iron dysregulation in Parkinson's disease. A) Tissue-level view of the substantia nigra pars compacta (SNc) showing suspected ante-mortem pathology: iron-laden (light blue circles), degenerating neuromelanin (black) containing neurons surrounded by activated microglia (blue). B) Subcellular view of nigral dopamine neuron showing pathophysiology and suspected mechanisms of iron dysregulation. Key features: decreased complex I activity; $\alpha$-synuclein aggregation, exacerbated by iron; increased TfR2 and DMT1 protein levels at plasma membrane; expression of TfR2 in nigral mitochondria; accumulation of oxidized Tf (red) in mitochondria - with associated reductive release of ferrous iron (blue); ROS-mediated release of ferrous iron from ferritin; Fenton chemistry (hydroxyl radical formation, $\cdot \mathrm{OH}$ ); decreased levels of reduced glutathione (GSH).

instead accumulate iron after phagocytosis of neurons that have accumulated iron.

Animal models of PD have helped answer this question by allowing investigators to track changes in iron homeostasis at earlier stages of parkinsonism. Mastroberardino and colleagues found that rotenone treatment of rats or monkeys resulted in iron accumulation in SNc dopamine neurons (shown by co-localization with tyrosine hydroxylase in the rat and with neuromelanin in the monkey) as well as microglia [13].
The globular iron staining that they observed in microglia, along with the proximity of microglia to dying dopamine neurons, supports the hypothesis that the increased iron content of microglia in the PD brain comes from phagocytosis of iron-laden dopamine neurons [13]. Iron accumulation in dopamine neurons of the SNc was also observed in the MPTP mouse model of PD [96].

The mechanism of iron accumulation in nigral dopamine neurons has only recently started to be eluci- 
dated (Fig. 4B). Mastroberardino and colleagues found that $\mathrm{Tf}$ accumulates in nigral dopamine neurons both in human PD and the rotenone rat model of PD, with much of this Tf localizing to mitochondria [13]. A large proportion of the nigral Tf was also found to be oxidized at cysteine residues that result in the formation of an intermolecular disulfide bond in close-proximity to the iron-binding site [13]. In vitro studies utilizing the xanthine/xanthine oxidase system for ROS generation demonstrated that oxidation of diferric-Tf caused it to release ferrous iron (reductive release of iron), suggesting that the oxidation of $\mathrm{Tf}$ observed in vivo has potential consequences with respect to redox-active iron release [13]. It would be expected that, under conditions of cellular iron overload, iron import machinery would be post-transcriptionally down-regulated. Interestingly, however, nigral dopamine neurons were found to express TfR 2 and relatively little TfR1 [13]. TfR2, unlike TfR1, is not regulated by intracellular iron levels, and its levels can remain elevated even in the face of marked cellular iron overload [97,98]. It has also been found, in a hepatocyte cell line that endogenously expresses TfR2, that Tf stabilizes TfR2 protein at the plasma membrane $[99,100]$. Indeed, TfR2 levels appeared increased in rat nigral dopamine neurons following rotenone treatment [13]. The confirmation of Tf/TfR2 dysregulation in the human PD brain strengthens the relevance of iron-related findings in the rotenone rat and monkey models of PD and suggests that delivery of toxic amounts of iron to nigral dopamine neuron mitochondria may contribute to the demise of these neurons in human PD. Therapeutically targeting this pathway (e.g., TfR2 down-regulation in nigral dopamine neurons) therefore may be a novel therapeutic avenue that obviates the need for systemic iron chelation.

Salazar and colleagues have shown that levels of the iron-related protein, DMT1+IRE, are upregulated in nigral dopamine neurons and microglia in human PD and in the MPTP mouse model of PD [96]. DMT1 transports $\mathrm{Fe}^{2+}$ both from the extracellular space into the cytosol and from the endocytotic vesicle (following Tf/TfR-mediated uptake) into the cytosol (Fig. 1). The observed upregulation of DMT1 therefore may release more $\mathrm{Fe}^{2+}$ into the cytosol, increasing the production of ROS through Fenton chemistry. To test this hypothesis, the authors treated with MPTP a genetically modified mouse $(\mathrm{mk} / \mathrm{mk})$ that bears a mutation in DMT1 that prevents it from transporting iron [96]. They found that MPTP-induced nigral dopamine neurons cell loss was attenuated in these mice as compared to wild-type mice [96]. Thus, DMT1 may also contribute to the vulnerability of nigral neurons.
Insofar as cells can safely sequester iron in a form that is not redox-active, they can stave off cytotoxicity. However, several factors may interfere with the cell's ability to do so. First, ROS of low oxidation potential (e.g., superoxide) can elicit release of ferrous iron from ferritin shells through a reductive mechanism, thereby perpetuating ROS formation through further Fenton chemistry [101]. In this manner, overproduction of ROS likely impairs the cell's ability to safely sequester iron. Second, human nigral dopamine neurons contain neuromelanin, which has been shown to bind several cellular substances including iron [102]. While this can serve to protect cells from the harmful effects of iron, when neuromelanin is over-saturated with iron (as in PD), some of the bound iron retains redox-active properties, allowing it to catalyze ROS formation [103, 104].

Excessive cellular iron, through its propensity to generate ROS, has consequences for many of the wellestablished pathogenic mechanisms of PD. Mitochondrial dysfunction was one of the earliest features identified in the study of subcellular pathology in PD. Mildly reduced activity of mitochondrial complex I was reported in the brain, platelets, and skeletal muscle of patients with idiopathic PD [105,106]. Further implicating mitochondrial dysfunction in PD pathogenesis is that fact that neurotoxins, such as MPTP and rotenone, that induce parkinsonism in humans, primates, and rodents act by partially inhibiting complex I and causing increased production of ROS. ROS have been shown to act in a feed-forward manner as both an effect and cause of mitochondrial dysfunction. Therefore, additional ROS derived from iron dysregulation likely exacerbate mitochondrial dysfunction in PD. Iron also appears to contribute to the formation of Lewy bodies, intraneuronal proteinaceous inclusions that contain the aggregationprone protein $\alpha$-synuclein and are considered to be the pathological hallmark of PD. Specifically, iron has also been shown to associate with $\alpha$-synuclein and increase its likelihood of aggregating, thereby potentiating its cytotoxic effects [107].

Based on these well-established findings of iron dysregulation in and suspected contribution to PD pathogenesis, there has been an increasing amount of investigation into the use of therapeutics targeting brain iron dysregulation in PD. The approaches studied to date can be broadly categorized into pharmacological and genetic iron chelation.

A fundamental concern in using pharmacological therapies in the treatment of PD is the difficulty in traversing the BBB. The selective permeability of 
the BBB limits entry of many drugs, and forces the use of higher doses of poorly brain-permeable drugs, leading to unintended side-effects in the periphery. Though widely used for experimental purposes on cells, the classical iron chelator desferrioxamine has poor BBB penetration, which limits its therapeutic potential. While effort has been put into testing known iron chelators with better BBB penetration for efficacy in neurodegeneration (e.g., clioquinol, PBT2; [86]), there has also been an effort to create multifunctional, brain-permeable drugs that simultaneously target several pathologies in addition to iron dysregulation in neurodegenerative disease.

Youdim's group has synthesized and partially characterized, both in vitro and in vivo, the multifunctional compounds VK-28 [108] and its derivative M30 [109]. M30 contains the propargylamine moiety of the MAO inhibitor, rasagiline - a drug that may be neuroprotective in the treatment of PD [110] - as well as an iron-chelating moiety [109]. While some of these studies have shown therapeutic benefit in animal models of neurodegeneration when used in a pretreatment paradigm [109], PD patients present clinically well after the degenerative process has commenced. Thus, studies demonstrating neuroprotection in a pretreatment paradigm may have little bearing on neuroprotection in human disease (although it is hoped that this is not the case).

Recently, Gal and colleagues found that administration of M30 to mice after they received MPTP treatment led to increased striatal dopamine levels, increased striatal TH levels and activity, and, surprisingly, an increase in TH-immunoreactive cell count in the SN [111]. While such results are encouraging, there are limitations in using acute neurotoxin models to evaluate therapeutic interventions intended for a chronic disease such as PD. Validation of these beneficial effects in a chronic animal model of PD using both pathological and behavioral endpoints would increase the likelihood that the compound would be neuroprotective in human PD.

Some investigators have used a genetic approach to chelate iron in an attempt to reduce iron-associated pathology in PD. Young transgenic mice (2-6 months old) overexpressing human $\mathrm{Ft}-\mathrm{H}$ driven by the human TH promoter were found to be more resistant to MPTP toxicity than non-transgenic littermates on a number of measures including nigral dopamine neuron loss, striatal dopamine levels, and nigral GSH content [112]. Interestingly, as these transgenic mice aged (8-16 months old), they developed a progressive neurodegenerative phenotype in the absence of MPTP treatment [113]. More recently, these researchers have contended that such chronic in vivo expression of $\mathrm{Ft}-\mathrm{H}$ expands the labile iron pool, making more redox active iron available for Fenton chemistry [114]. Thus, this study illustrates an important challenge to implementing iron chelation therapy; namely, that cellular iron homeostasis machinery is sensitive to exogenous perturbations and unintended toxicity related to iron dysregulation can ensue.

\section{CONCLUSIONS}

The ability of mitochondria to synthesize ISCs and heme is crucial not only for the myriad cellular proteins that rely on these prosthetic groups for their functions, but also for proper balance of iron homeostasis through IRPs. Mitochondrial production of ISCs may be impaired in neurodegenerative diseases, where mitochondrial dysfunction and oxidative stress commonly occur together. This, in turn, threatens the normal functioning of the IRP system, which relies, in part, on successful production of ISCs.

As discussed, some features of brain iron accumulation are common across different neurodegenerative diseases, while other features differ. Understanding the precise mechanism of iron dysregulation in each disease will allow for the development of more specifically-targeted therapeutics. Iron chelation has been used as a research tool to prove the importance of iron accumulation in disease pathogenesis and progression, and this strategy may also be a promising therapeutic approach. However, if iron chelator therapies are to be successful, they must not disrupt normal cellular iron homeostasis. In this regard, 'too much of a good thing' may be hazardous; when FtMt was overexpressed in a human cell line, it was found to sensitize the cells to pro-oxidants [42], and when Ft-H was overexpressed in mice they developed iron dysregulation and neurodegeneration [113]. Based on in vitro studies using pharmacological iron chelators that preferentially target different subcellular compartments, Li and colleagues have drawn attention to the importance of maintaining the proper balance of iron levels subcellularly [115]. Therefore, a better understanding of the basic molecular mechanisms of cellular and subcellular iron homeostasis in the brain is critical to the future success of therapies that target iron dysregulation in neurodegenerative diseases. 


\section{ACKNOWLEDGMENTS}

This work was supported by NIH grant 1P01NS0598 06 and the American Parkinson Disease Association Advanced Center for Parkinson Research at the University of Pittsburgh.

Authors' disclosures available online (http://www.jalz.com/disclosures/view.php?id=425).

\section{REFERENCES}

[1] Herrero-Mendez A, Almeida A, Fernandez E, Maestre C, Moncada S, Bolanos JP (2009) The bioenergetic and antioxidant status of neurons is controlled by continuous degradation of a key glycolytic enzyme by APC/C-Cdh1. Nat Cell Biol 11, 747-752.

[2] Sheftel A, Stehling O, Lill R (2010) Iron-sulfur proteins in health and disease. Trends Endocrinol Metab 21, 302-314.

[3] Furuyama K, Kaneko K, Vargas PD (2007) Heme as a magnificent molecule with multiple missions: heme determines its own fate and governs cellular homeostasis. Tohoku J Exp Med 213, 1-16.

[4] MacKenzie EL, Iwasaki K, Tsuji Y (2008) Intracellular iron transport and storage: from molecular mechanisms to health implications. Antioxid Redox Signal 10, 997-1030.

[5] Garrick MD, Garrick LM (2009) Cellular iron transport. Biochim Biophys Acta 1790, 309-325.

[6] Ohgami RS, Campagna DR, Greer EL, Antiochos B, McDonald A, Chen J, Sharp JJ, Fujiwara Y, Barker JE, Fleming MD (2005) Identification of a ferrireductase required for efficient transferrin-dependent iron uptake in erythroid cells. Nat Genet 37, 1264-1269.

[7] Ohgami RS, Campagna DR, Antiochos B, Wood EB, Sharp JJ, Barker JE, Fleming MD (2005) nm1054: a spontaneous, recessive, hypochromic, microcytic anemia mutation in the mouse. Blood 106, 3625-3631.

[8] Hentze MW, Muckenthaler MU, Andrews NC (2004) Balancing acts: molecular control of mammalian iron metabolism. Cell 117, 285-297.

[9] Shvartsman M, Kikkeri R, Shanzer A, Cabantchik ZI (2007) Non-transferrin-bound iron reaches mitochondria by a chelator-inaccessible mechanism: biological and clinical implications. Am J Physiol Cell Physiol 293, C1383-1394.

[10] Kruszewski M (2003) Labile iron pool: the main determinant of cellular response to oxidative stress. Mutat Res 531, 81-92.

[11] Zhang AS, Sheftel AD, Ponka P (2005) Intracellular kinetics of iron in reticulocytes: evidence for endosome involvement in iron targeting to mitochondria. Blood 105, 368-375.

[12] Sheftel AD, Zhang AS, Brown C, Shirihai OS, Ponka P (2007) Direct interorganellar transfer of iron from endosome to mitochondrion. Blood 110, 125-132.

[13] Mastroberardino PG, Hoffman EK, Horowitz MP, Betarbet R, Taylor G, Cheng D, Na HM, Gutekunst CA, Gearing M, Trojanowski JQ, Anderson M, Chu CT, Peng J, Greenamyre JT (2009) A novel transferrin/TfR2-mediated mitochondrial iron transport system is disrupted in Parkinson's disease. Neurobiol Dis 34, 417-431.

[14] Shaw GC, Cope JJ, Li L, Corson K, Hersey C, Ackermann GE, Gwynn B, Lambert AJ, Wingert RA, Traver D, Trede NS, Barut BA, Zhou Y, Minet E, Donovan A, Brownlie A,
Balzan R, Weiss MJ, Peters LL, Kaplan J, Zon LI, Paw BH (2006) Mitoferrin is essential for erythroid iron assimilation. Nature 440, 96-100.

[15] Paradkar PN, Zumbrennen KB, Paw BH, Ward DM, Kaplan J (2009) Regulation of mitochondrial iron import through differential turnover of mitoferrin 1 and mitoferrin 2. Mol Cell Biol 29, 1007-1016.

[16] Chen W, Paradkar PN, Li L, Pierce EL, Langer NB, Takahashi-Makise N, Hyde BB, Shirihai OS, Ward DM, Kaplan J, Paw BH (2009) Abcb10 physically interacts with mitoferrin-1 (Slc25a37) to enhance its stability and function in the erythroid mitochondria. Proc Natl Acad Sci U S A 106, 16263-16268.

[17] Lill R, Muhlenhoff U (2008) Maturation of iron-sulfur proteins in eukaryotes: mechanisms, connected processes, and diseases. Annu Rev Biochem 77, 669-700.

[18] Ajioka RS, Phillips JD, Kushner JP (2006) Biosynthesis of heme in mammals. Biochim Biophys Acta 1763, 723-736.

[19] Sheftel AD, Lill R (2009) The power plant of the cell is also a smithy: the emerging role of mitochondria in cellular iron homeostasis. Ann Med 41, 82-99.

[20] Wingert RA, Galloway JL, Barut B, Foott H, Fraenkel P, Axe JL, Weber GJ, Dooley K, Davidson AJ, Schmid B, Paw BH, Shaw GC, Kingsley P, Palis J, Schubert H, Chen O, Kaplan J, Zon LI (2005) Deficiency of glutaredoxin 5 reveals Fe-S clusters are required for vertebrate haem synthesis. Nature 436, 1035-1039.

[21] Camaschella C, Campanella A, De Falco L, Boschetto L, Merlini R, Silvestri L, Levi S, Iolascon A (2007) The human counterpart of zebrafish shiraz shows sideroblastic-like microcytic anemia and iron overload. Blood 110, 1353-1358.

[22] Bych K, Kerscher S, Netz DJ, Pierik AJ, Zwicker K, Huynen MA, Lill R, Brandt U, Balk J (2008) The iron-sulphur protein Ind1 is required for effective complex I assembly. EMBO $J$ 27, 1736-1746.

[23] Sheftel AD, Stehling O, Pierik AJ, Netz DJ, Kerscher S, Elsasser HP, Wittig I, Balk J, Brandt U, Lill R (2009) Human ind1, an iron-sulfur cluster assembly factor for respiratory complex I. Mol Cell Biol 29, 6059-6073.

[24] Pondarre C, Antiochos BB, Campagna DR, Clarke SL, Greer EL, Deck KM, McDonald A, Han AP, Medlock A, Kutok JL, Anderson SA, Eisenstein RS, Fleming MD (2006) The mitochondrial ATP-binding cassette transporter Abcb7 is essential in mice and participates in cytosolic iron-sulfur cluster biogenesis. Hum Mol Genet 15, 953-964.

[25] Cavadini P, Biasiotto G, Poli M, Levi S, Verardi R, Zanella I, Derosas M, Ingrassia R, Corrado M, Arosio P (2007) RNA silencing of the mitochondrial ABCB7 transporter in HeLa cells causes an iron-deficient phenotype with mitochondrial iron overload. Blood 109, 3552-3559.

[26] Krishnamurthy PC, Du G, Fukuda Y, Sun D, Sampath J, Mercer KE, Wang J, Sosa-Pineda B, Murti KG, Schuetz JD (2006) Identification of a mammalian mitochondrial porphyrin transporter. Nature 443, 586-589.

[27] Levi S, Rovida E (2009) The role of iron in mitochondrial function. Biochim Biophys Acta 1790, 629-636.

[28] Rouault TA, Tong WH (2008) Iron-sulfur cluster biogenesis and human disease. Trends Genet 24, 398-407.

[29] Wu CK, Dailey HA, Rose JP, Burden A, Sellers VM, Wang BC (2001) The 2.0 A structure of human ferrochelatase, the terminal enzyme of heme biosynthesis. Nat Struct Biol 8, 156-160.

[30] Dailey HA, Finnegan MG, Johnson MK (1994) Human ferrochelatase is an iron-sulfur protein. Biochemistry 33, 403- 
407.

[31] Lange H, Muhlenhoff U, Denzel M, Kispal G, Lill R (2004) The heme synthesis defect of mutants impaired in mitochondrial iron-sulfur protein biogenesis is caused by reversible inhibition of ferrochelatase. J Biol Chem 279, 29101-29108.

[32] Nilsson R, Schultz IJ, Pierce EL, Soltis KA, Naranuntarat A, Ward DM, Baughman JM, Paradkar PN, Kingsley PD, Culotta VC, Kaplan J, Palis J, Paw BH, Mootha VK (2009) Discovery of genes essential for heme biosynthesis through large-scale gene expression analysis. Cell Metab 10, 119130.

[33] Boveris A, Chance B (1973) The mitochondrial generation of hydrogen peroxide. General properties and effect of hyperbaric oxygen. Biochem J 134, 707-716.

[34] Imlay JA, Fridovich I (1991) Assay of metabolic superoxide production in Escherichia coli. J Biol Chem 266, 6957-6965.

[35] Cadenas E, Boveris A, Ragan CI, Stoppani AO (1977) Production of superoxide radicals and hydrogen peroxide by NADH-ubiquinone reductase and ubiquinol-cytochrome $c$ reductase from beef-heart mitochondria. Arch Biochem Biophys 180, 248-257.

[36] Halliwell BG, Gutteridge JMC (2007) Free Radicals in Biology and Medicine (4th). Oxford University Press, USA.

[37] Levi S, Corsi B, Bosisio M, Invernizzi R, Volz A, Sanford D, Arosio P, Drysdale J (2001) A human mitochondrial ferritin encoded by an intronless gene. J Biol Chem 276, 2443724440.

[38] Santambrogio P, Biasiotto G, Sanvito F, Olivieri S, Arosio P, Levi S (2007) Mitochondrial ferritin expression in adult mouse tissues. J Histochem Cytochem 55, 1129-1137.

[39] Cazzola M, Invernizzi R, Bergamaschi G, Levi S, Corsi B, Travaglino E, Rolandi V, Biasiotto G, Drysdale J, Arosio P (2003) Mitochondrial ferritin expression in erythroid cells from patients with sideroblastic anemia. Blood 101, 19962000.

[40] Campanella A, Rovelli E, Santambrogio P, Cozzi A, Taroni F, Levi S (2009) Mitochondrial ferritin limits oxidative damage regulating mitochondrial iron availability: hypothesis for a protective role in Friedreich ataxia. Hum Mol Genet 18, 1-11.

[41] Nie G, Sheftel AD, Kim SF, Ponka P (2005) Overexpression of mitochondrial ferritin causes cytosolic iron depletion and changes cellular iron homeostasis. Blood 105, 2161-2167.

[42] Lu Z, Nie G, Li Y, Soe-Lin S, Tao Y, Cao Y, Zhang Z, Liu N, Ponka P, Zhao B (2009) Overexpression of mitochondrial ferritin sensitizes cells to oxidative stress via an iron-mediated mechanism. Antioxid Redox Signal 11, 1791-1803.

[43] Shi Z, Nie G, Duan XL, Rouault T, Wu WS, Ning B, Zhang N, Chang YZ, Zhao B (2010) Neuroprotective mechanism of mitochondrial ferritin on 6-hydroxydopamine induced dopaminergic cell damage: implication for neuroprotection in Parkinson's disease. Antioxid Redox Signal, in press.

[44] Shan Y, Napoli E, Cortopassi G (2007) Mitochondrial frataxin interacts with ISD11 of the NFS1/ISCU complex and multiple mitochondrial chaperones. Hum Mol Genet 16, 929941.

[45] Gakh O, Adamec J, Gacy AM, Twesten RD, Owen WG, Isaya G (2002) Physical evidence that yeast frataxin is an iron storage protein. Biochemistry 41, 6798-6804.

[46] Aloria K, Schilke B, Andrew A, Craig EA (2004) Ironinduced oligomerization of yeast frataxin homologue Yfh1 is dispensable in vivo. EMBO Rep 5, 1096-1101.

[47] Rutherford JC, Bird AJ (2004) Metal-responsive transcription factors that regulate iron, zinc, and copper homeostasis in eukaryotic cells. Eukaryot Cell 3, 1-13.

[48] Muckenthaler MU, Galy B, Hentze MW (2008) Systemic iron homeostasis and the iron-responsive element/ironregulatory protein (IRE/IRP) regulatory network. Annu Rev Nutr 28, 197-213.

[49] Rogers JT, Randall JD, Cahill CM, Eder PS, Huang X, Gunshin H, Leiter L, McPhee J, Sarang SS, Utsuki T, Greig NH, Lahiri DK, Tanzi RE, Bush AI, Giordano T, Gullans SR (2002) An iron-responsive element type II in the 5'untranslated region of the Alzheimer's amyloid precursor protein transcript. $J$ Biol Chem 277, 45518-45528.

[50] Friedlich AL, Tanzi RE, Rogers JT (2007) The 5'untranslated region of Parkinson's disease alpha-synuclein messengerRNA contains a predicted iron responsive element. Mol Psychiatry 12, 222-223.

[51] Butt J, Kim HY, Basilion JP, Cohen S, Iwai K, Philpott CC, Altschul S, Klausner RD, Rouault TA (1996) Differences in the RNA binding sites of iron regulatory proteins and potential target diversity. Proc Natl Acad Sci U S A 93, 43454349

[52] Guo B, Brown FM, Phillips JD, Yu Y, Leibold EA (1995) Characterization and expression of iron regulatory protein 2 (IRP2). Presence of multiple IRP2 transcripts regulated by intracellular iron levels. J Biol Chem 270, 16529-16535.

[53] Dupuy J, Volbeda A, Carpentier P, Darnault C, Moulis JM, Fontecilla-Camps JC (2006) Crystal structure of human iron regulatory protein 1 as cytosolic aconitase. Structure 14, 129139.

[54] Nunez-Millacura C, Tapia V, Munoz P, Maccioni RB, Nunez MT (2002) An oxidative stress-mediated positive-feedback iron uptake loop in neuronal cells. J Neurochem 82, 240-248.

[55] Walden WE, Selezneva AI, Dupuy J, Volbeda A, FontecillaCamps JC, Theil EC, Volz K (2006) Structure of dual function iron regulatory protein 1 complexed with ferritin IRE-RNA. Science 314, 1903-1908.

[56] Meyron-Holtz EG, Ghosh MC, Iwai K, LaVaute T, Brazzolotto X, Berger UV, Land W, Ollivierre-Wilson H, Grinberg A, Love P, Rouault TA (2004) Genetic ablations of iron regulatory proteins 1 and 2 reveal why iron regulatory protein 2 dominates iron homeostasis. EMBO J 23, 386-395.

[57] LaVaute T, Smith S, Cooperman S, Iwai K, Land W, MeyronHoltz E, Drake SK, Miller G, Abu-Asab M, Tsokos M, Switzer R, 3rd, Grinberg A, Love P, Tresser N, Rouault TA (2001) Targeted deletion of the gene encoding iron regulatory protein- 2 causes misregulation of iron metabolism and neurodegenerative disease in mice. Nat Genet 27, 209-214.

[58] Galy B, Ferring D, Minana B, Bell O, Janser HG, Muckenthaler M, Schumann K, Hentze MW (2005) Altered body iron distribution and microcytosis in mice deficient in iron regulatory protein 2 (IRP2). Blood 106, 2580-2589.

[59] Meyron-Holtz EG, Ghosh MC, Rouault TA (2004) Mammalian tissue oxygen levels modulate iron-regulatory protein activities in vivo. Science 306, 2087-2090.

[60] Ghosh MC, Tong WH, Zhang D, Ollivierre-Wilson H, Singh A, Krishna MC, Mitchell JB, Rouault TA (2008) Tempolmediated activation of latent iron regulatory protein activity prevents symptoms of neurodegenerative disease in IRP2 knockout mice. Proc Natl Acad Sci U S A 105, 12028-12033.

[61] Salahudeen AA, Thompson JW, Ruiz JC, Ma HW, Kinch LN, Li Q, Grishin NV, Bruick RK (2009) An E3 ligase possessing an iron-responsive hemerythrin domain is a regulator of iron homeostasis. Science 326, 722-726.

[62] Vashisht AA, Zumbrennen KB, Huang X, Powers DN, Durazo A, Sun D, Bhaskaran N, Persson A, Uhlen M, Sangfelt 
O, Spruck C, Leibold EA, Wohlschlegel JA (2009) Control of iron homeostasis by an iron-regulated ubiquitin ligase. Science 326, 718-721.

[63] Kuhn LC (2009) How iron controls iron. Cell Metab 10, 439-441.

[64] Hallgren B, Sourander P (1958) The effect of age on the non-haemin iron in the human brain. J Neurochem $3,41-51$.

[65] Zecca L, Youdim MB, Riederer P, Connor JR, Crichton RR (2004) Iron, brain ageing and neurodegenerative disorders. Nat Rev Neurosci 5, 863-873.

[66] Badaracco ME, Siri MV, Pasquini JM (2010) Oligodendrogenesis: The role of iron. Biofactors 36, 98-102.

[67] Zechel S, Huber-Wittmer K, von Bohlen und Halbach O (2006) Distribution of the iron-regulating protein hepcidin in the murine central nervous system. J Neurosci Res 84, 790-800.

[68] Wang SM, Fu LJ, Duan XL, Crooks DR, Yu P, Qian ZM, Di XJ, Li J, Rouault TA, Chang YZ Role of hepcidin in murine brain iron metabolism. Cell Mol Life Sci 67, 123-133.

[69] Wu LJ, Leenders AG, Cooperman S, Meyron-Holtz E, Smith S, Land W, Tsai RY, Berger UV, Sheng ZH, Rouault TA (2004) Expression of the iron transporter ferroportin in synaptic vesicles and the blood-brain barrier. Brain Res 1001, 108-117.

[70] Berg D, Hochstrasser H (2006) Iron metabolism in Parkinsonian syndromes. Mov Disord 21, 1299-1310.

[71] Ke Y, Ming Qian Z (2003) Iron misregulation in the brain: a primary cause of neurodegenerative disorders. Lancet Neurol 2, 246-253.

[72] Querfurth HW, LaFerla FM Alzheimer's disease. $N$ Engl $J$ Med 362, 329-344.

[73] Lovell MA, Robertson JD, Teesdale WJ, Campbell JL, Markesbery WR (1998) Copper, iron and zinc in Alzheimer's disease senile plaques. J Neurol Sci 158, 47-52.

[74] Zatta P, Drago D, Bolognin S, Sensi SL (2009) Alzheimer's disease, metal ions and metal homeostatic therapy. Trends Pharmacol Sci 30, 346-355.

[75] Smith MA, Harris PL, Sayre LM, Perry G (1997) Iron accumulation in Alzheimer disease is a source of redox-generated free radicals. Proc Natl Acad Sci U S A 94, 9866-9868.

[76] Connor JR, Snyder BS, Beard JL, Fine RE, Mufson EJ (1992) Regional distribution of iron and iron-regulatory proteins in the brain in aging and Alzheimer's disease. J Neurosci Res 31, 327-335.

[77] Altamura S, Muckenthaler MU (2009) Iron toxicity in diseases of aging: Alzheimer's disease, Parkinson's disease and atherosclerosis. J Alzheimers Dis 16, 879-895.

[78] Nakamura M, Shishido N, Nunomura A, Smith MA, Perry G, Hayashi Y, Nakayama K, Hayashi T (2007) Three histidine residues of amyloid-beta peptide control the redox activity of copper and iron. Biochemistry 46, 12737-12743.

[79] Avramovich-Tirosh Y, Amit T, Bar-Am O, Weinreb O, Youdim MB (2008) Physiological and pathological aspects of Abeta in iron homeostasis via 5'UTR in the APP mRNA and the therapeutic use of iron-chelators. BMC Neurosci 9(Suppl 2), S2.

[80] House E, Collingwood J, Khan A, Korchazkina O, Berthon G, Exley C (2004) Aluminium, iron, zinc and copper influence the in vitro formation of amyloid fibrils of Abeta42 in a manner which may have consequences for metal chelation therapy in Alzheimer's disease. J Alzheimers Dis 6, 291-301.

[81] Yamamoto A, Shin RW, Hasegawa K, Naiki H, Sato H, Yoshimasu F, Kitamoto T (2002) Iron (III) induces aggregation of hyperphosphorylated tau and its reduction to iron (II) re- verses the aggregation: implications in the formation of neurofibrillary tangles of Alzheimer's disease. J Neurochem 82, 1137-1147.

[82] Zheng W, Xin N, Chi ZH, Zhao BL, Zhang J, Li JY, Wang ZY (2009) Divalent metal transporter 1 is involved in amyloid precursor protein processing and Abeta generation. FASEB $J$ 23, 4207-4217.

[83] Crapper McLachlan DR, Dalton AJ, Kruck TP, Bell MY, Smith WL, Kalow W, Andrews DF (1991) Intramuscular desferrioxamine in patients with Alzheimer's disease. Lancet 337, 1304-1308.

[84] Cherny RA, Atwood CS, Xilinas ME, Gray DN, Jones WD, McLean CA, Barnham KJ, Volitakis I, Fraser FW, Kim Y, Huang X, Goldstein LE, Moir RD, Lim JT, Beyreuther K, Zheng H, Tanzi RE, Masters CL, Bush AI (2001) Treatment with a copper-zinc chelator markedly and rapidly inhibits beta-amyloid accumulation in Alzheimer's disease transgenic mice. Neuron 30, 665-676.

[85] Ritchie CW, Bush AI, Mackinnon A, Macfarlane S, Mastwyk M, MacGregor L, Kiers L, Cherny R, Li QX, Tammer A, Carrington D, Mavros C, Volitakis I, Xilinas M, Ames D, Davis S, Beyreuther K, Tanzi RE, Masters CL (2003) Metalprotein attenuation with iodochlorhydroxyquin (clioquinol) targeting Abeta amyloid deposition and toxicity in Alzheimer disease: a pilot phase 2 clinical trial. Arch Neurol 60, 16851691

[86] Adlard PA, Cherny RA, Finkelstein DI, Gautier E, Robb E, Cortes M, Volitakis I, Liu X, Smith JP, Perez K, Laughton K, Li QX, Charman SA, Nicolazzo JA, Wilkins S, Deleva K, Lynch T, Kok G, Ritchie CW, Tanzi RE, Cappai R, Masters CL, Barnham KJ, Bush AI (2008) Rapid restoration of cognition in Alzheimer's transgenic mice with 8-hydroxy quinoline analogs is associated with decreased interstitial Abeta. Neuron 59, 43-55.

[87] Avramovich-Tirosh Y, Amit T, Bar-Am O, Zheng H, Fridkin M, Youdim MB (2007) Therapeutic targets and potential of the novel brain- permeable multifunctional iron chelatormonoamine oxidase inhibitor drug, M-30, for the treatment of Alzheimer's disease. J Neurochem 100, 490-502.

[88] Reznichenko L, Amit T, Zheng H, Avramovich-Tirosh Y, Youdim MB, Weinreb O, Mandel S (2006) Reduction of iron-regulated amyloid precursor protein and beta-amyloid peptide by (-)-epigallocatechin-3-gallate in cell cultures: implications for iron chelation in Alzheimer's disease. $\mathrm{J} \mathrm{Neu-}$ rochem $\mathbf{9 7}$, 527-536.

[89] Bandyopadhyay S, Ni J, Ruggiero A, Walshe K, Rogers MS, Chattopadhyay N, Glicksman MA, Rogers JT (2006) A highthroughput drug screen targeted to the 5'untranslated region of Alzheimer amyloid precursor protein mRNA. J Biomol Screen 11, 469-480.

[90] Lhermitte J, Kraus, W.M., and McAlpine, D. (1924) On the occurrence of abnormal deposits of iron in the brain in parkinsonism with special reference to its localisation. $J$ Neurol Psychopathol 5, 195-208.

[91] Berg D (2006) In vivo detection of iron and neuromelanin by transcranial sonography - a new approach for early detection of substantia nigra damage. J Neural Transm 113, 775-780.

[92] Berg D, Hochstrasser H, Schweitzer KJ, Riess O (2006) Disturbance of iron metabolism in Parkinson's disease - ultrasonography as a biomarker. Neurotox Res 9, 1-13.

[93] Friedman A, Galazka-Friedman J, Koziorowski D (2009) Iron as a cause of Parkinson disease - a myth or a well established hypothesis? Parkinsonism Relat Disord 15(Suppl 3), S212-214. 
[94] Gotz ME, Double K, Gerlach M, Youdim MB, Riederer P (2004) The relevance of iron in the pathogenesis of Parkinson's disease. Ann N Y Acad Sci 1012, 193-208.

[95] Oakley AE, Collingwood JF, Dobson J, Love G, Perrott HR, Edwardson JA, Elstner M, Morris CM (2007) Individual dopaminergic neurons show raised iron levels in Parkinson disease. Neurology 68, 1820-1825.

[96] Salazar J, Mena N, Hunot S, Prigent A, Alvarez-Fischer D, Arredondo M, Duyckaerts C, Sazdovitch V, Zhao L, Garrick LM, Nunez MT, Garrick MD, Raisman-Vozari R, Hirsch EC (2008) Divalent metal transporter 1 (DMT1) contributes to neurodegeneration in animal models of Parkinson's disease. Proc Natl Acad Sci U S A 105, 18578-18583.

[97] Fleming RE, Migas MC, Holden CC, Waheed A, Britton RS, Tomatsu S, Bacon BR, Sly WS (2000) Transferrin receptor 2: continued expression in mouse liver in the face of iron overload and in hereditary hemochromatosis. Proc Natl Acad Sci U S A 97, 2214-2219.

[98] Mifuji R, Kobayashi Y, Ma N, Qiang QL, Urawa N, Horiike S, Iwasa M, Kaito M, Malavasi F, Adachi Y (2006) Role of transferrin receptor 2 in hepatic accumulation of iron in patients with chronic hepatitis C. J Gastroenterol Hepatol 21, 144-151.

[99] Johnson MB, Enns CA (2004) Diferric transferrin regulates transferrin receptor 2 protein stability. Blood 104, 4287-4293.

[100] Johnson MB, Chen J, Murchison N, Green FA, Enns CA (2007) Transferrin receptor 2: evidence for ligand-induced stabilization and redirection to a recycling pathway. Mol Biol Cell 18, 743-754.

[101] Double KL, Maywald M, Schmittel M, Riederer P, Gerlach M (1998) In vitro studies of ferritin iron release and neurotoxicity. J Neurochem 70, 2492-2499.

[102] Zecca L, Shima T, Stroppolo A, Goj C, Battiston GA, Gerbasi R, Sarna T, Swartz HM (1996) Interaction of neuromelanin and iron in substantia nigra and other areas of human brain. Neuroscience 73, 407-415.

[103] Jellinger K, Kienzl E, Rumpelmair G, Riederer P, Stachelberger H, Ben-Shachar D, Youdim MB (1992) Iron-melanin complex in substantia nigra of parkinsonian brains: an x-ray microanalysis. J Neurochem 59, 1168-1171.

[104] Faucheux BA, Martin ME, Beaumont C, Hauw JJ, Agid Y, Hirsch EC (2003) Neuromelanin associated redox-active iron is increased in the substantia nigra of patients with Parkinson's disease. $J$ Neurochem 86, 1142-1148.

[105] Yoshino H, Nakagawa-Hattori Y, Kondo T, Mizuno Y (1992) Mitochondrial complex I and II activities of lymphocytes and platelets in Parkinson's disease. J Neural Transm Park Dis Dement Sect 4, 27-34.

106] Krige D, Carroll MT, Cooper JM, Marsden CD, Schapira AH (1992) Platelet mitochondrial function in Parkinson's disease. The Royal Kings and Queens Parkinson Disease Research Group. Ann Neurol 32, 782-788.

[107] Uversky VN (2007) Neuropathology, biochemistry, and biophysics of alpha-synuclein aggregation. J Neurochem 103, 17-37.

108] Shachar DB, Kahana N, Kampel V, Warshawsky A, Youdim MB (2004) Neuroprotection by a novel brain permeable iron chelator, VK-28, against 6-hydroxydopamine lession in rats. Neuropharmacology 46, 254-263.

[109] Gal S, Fridkin M, Amit T, Zheng H, Youdim MB (2006) M30, a novel multifunctional neuroprotective drug with potent iron chelating and brain selective monoamine oxidase-ab inhibitory activity for Parkinson's disease. J Neural Transm Suppl, 447-456.

[110] Malaty IA, Fernandez HH (2009) Role of rasagiline in treating Parkinson's disease: Effect on disease progression. Ther Clin Risk Manag 5, 413-419.

[111] Gal S, Zheng H, Fridkin M, Youdim MB Restoration of nigrostriatal dopamine neurons in post-MPTP treatment by the novel multifunctional brain-permeable iron chelatormonoamine oxidase inhibitor drug, M30. Neurotox Res 17, 15-27.

[112] Kaur D, Yantiri F, Rajagopalan S, Kumar J, Mo JQ, Boonplueang R, Viswanath V, Jacobs R, Yang L, Beal MF, DiMonte D, Volitaskis I, Ellerby L, Cherny RA, Bush AI, Andersen JK (2003) Genetic or pharmacological iron chelation prevents MPTP-induced neurotoxicity in vivo: a novel therapy for Parkinson's disease. Neuron 37, 899-909.

[113] Kaur D, Rajagopalan S, Chinta S, Kumar J, Di Monte D, Cherny RA, Andersen JK (2007) Chronic ferritin expression within murine dopaminergic midbrain neurons results in a progressive age-related neurodegeneration. Brain Res 1140 , 188-194.

[114] Kaur D, Rajagopalan S, Andersen JK (2009) Chronic expression of $\mathrm{H}$-ferritin in dopaminergic midbrain neurons results in an age-related expansion of the labile iron pool and subsequent neurodegeneration: implications for Parkinson's disease. Brain Res 1297, 17-22.

[115] Li K, Besse EK, Ha D, Kovtunovych G, Rouault TA (2008) Iron-dependent regulation of frataxin expression: implications for treatment of Friedreich ataxia. Hum Mol Genet 17, 2265-2273. 